\title{
CORRECTING ENGINE TESTS FOR HUMIDITY
}

\author{
By Donald B. Brooks
}

ABSTRACT

Data obtained on a 6-cylinder automobile engine indicate a loss of engine power with increasing humidity proportional to the volumetric loss of oxygen content of the atmosphere. It is shown that power and fuel consumption may be corrected by subtracting observed water vapor pressure from atmospheric pressure and using the result in place of barometric pressure in the usual correction formula. The humidity correction may be as large as that due to changes in barometric pressure.

Simple nomograms are presented for obtaining the humidity correction, both near sea level and at higher altitudes. An appendix gives methods of computation of these nomograms.

\section{CONTENTS}

Page

II. Test apparatus and procedure

1. Test series No. 1.... 797

2. Test series No. 2_. 797

3. Test series No. 3...

III. Discussion of results

IV. Humidity correction chart

V. Conclusions _._. 803

VI. Appendix-Method of computation of charts ...

\section{INTRODUCTION}

Tests made by A. W. Gardiner ${ }^{1}$ using a 1-cylinder engine having indicated that atmospheric humidity has a very appreciable effect on some phases of engine performance, a test program was undertaken at the Bureau of Standards further to study this effect, using a multicylinder engine.

\section{TEST APPARATUS AND PROCEDURE}

Tests were made on a 6-cylinder, 3-port, overhead valve engine of $3 \frac{1}{8}$-inch bore and $4 \frac{1}{2}$-inch stroke, coupled to a Sprague electric dynamometer and spark accelerometer. In the three series of tests three different fuels were used, being selected so as to give little or no detonation at optimum spark advance under any test condition.

Power measurements were made on the dynamometer and friction measurements by use of the spark accelerometer, ${ }^{2}$ the latter being

${ }_{1}$ See J. S. A. E., p. 155; February, 1929.

${ }_{2}$ Method described in paper by Brooks on Operating Factors and Engine Acceleration presented at S. A. E. annual meeting, January, 1929. See J. Soc. Automotive Eng., p. 130; August, 1929. 
checked against friction measurements on the dynamometer. Humidification was obtained by passing steam and cold air into a mixing chamber and thence to an air heater. Measurements of humidity were made by continuously passing a part of the carburetor air supply over calibrated dry and wet bulb thermometers graduated to $0.2^{\circ} \mathrm{F}$. Measurements of humidity are expressed as pressure of water vapor in $\mathrm{mm} \mathrm{Hg}$.

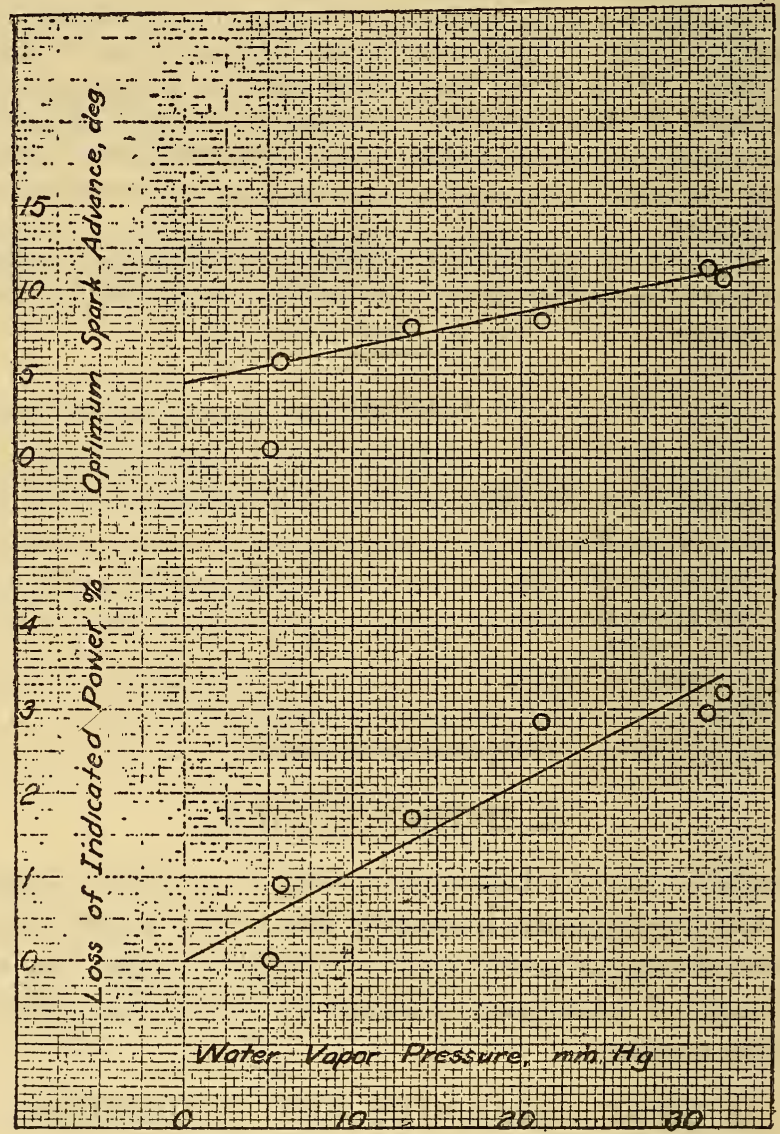

FIgURE 1.-Effect of humidity on engine performance

Tests were made at full throttle at an engine speed of 500 r. p. m. Cylinder and manifold jackets were maintained at the same temperature, this being from $60^{\circ}$ to $80^{\circ} \mathrm{C}$. in the different series of tests but being constant for any one series.

In the first two series of tests readings were taken at from 6 to 8 spark advances for each humidity and air-fuel ratio. From the results, plotted against spark advance, faired values of maximum power and optimum spark advance were obtained. In the third test series optimum advance was found by trial. 


\section{TEST SERIES NO. 1}

The tests of this series were made with a mixture of 2 parts of eastern domestic aviation gasoline to 1 part of motor benzol. A fixed carburetor adjustment was used, giving an air-fuel ratio of about 13.5. Carburetor air temperature was maintained at $30^{\circ} \mathrm{C}$.

Optimum power and spark advance were determined at humidities from $5.1 \mathrm{~mm} \mathrm{Hg}$ to saturation $(31.9 \mathrm{~mm} \mathrm{Hg})$. Figure 1 shows the results, plotted against water vapor pressure.

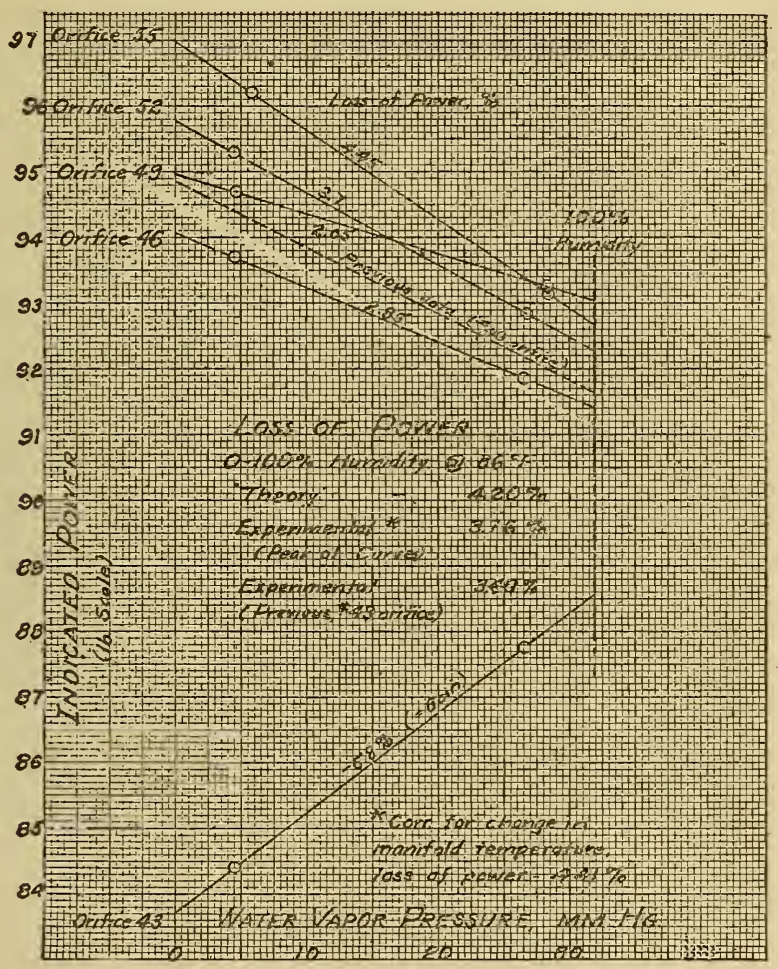

Figure 2.-Effect of humidity on power

\section{TEST SERIES NO. 2}

The tests of this series were made with a mixture of equal parts of eastern domestic aviation gasoline and motor benzol. A series of 5 carburetor metering jets were used, giving air-fuel ratios from about 12 to about 16 . Carburetor air temperature was maintained at $30^{\circ} \mathrm{C}$.

With each air-fuel ratio optimum power and spark advance were determined at two humidities, 4.5 and $27 \mathrm{~mm} \mathrm{Hg}$, respectively. Figure 2 shows the results, plotted against water-vapor pressure. It is notable that with orifice 43 an apparent increase of power with 
humidity is shown. This is the leanest orifice used; the apparent increase in power seems to be due to automatic enrichment of the mixture at higher humidities.

\section{TEST SERIES NO. 3}

The tests of this series were made with a commercial brand of aviation gasoline approximately equal in antiknock value to a mixture of equal parts of eastern domestic aviation gasoline and motor benzol.

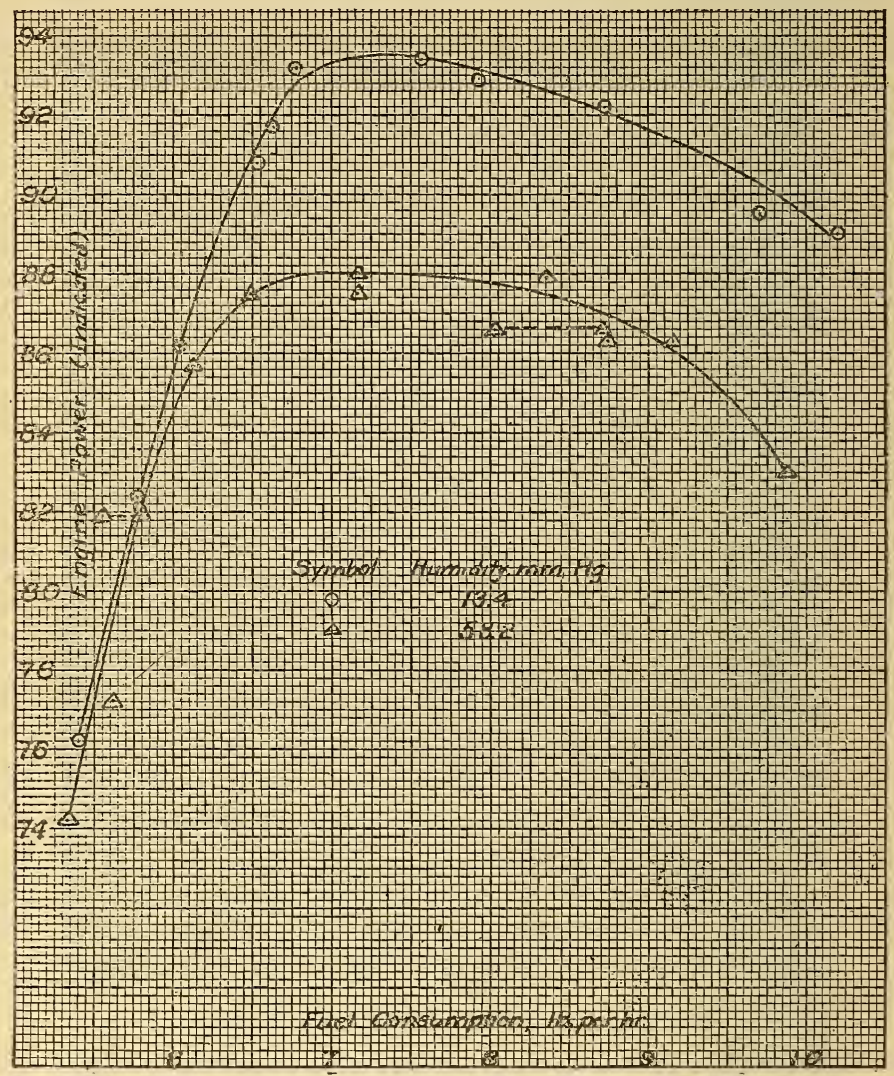

FIGURE 3.-Effect of humidity on power

For this series of tests the carburetor was equipped with a needle valve, and tests were made over a range corresponding roughly to air-fuel ratios of 9 to 17 . Carburetor air temperature was maintained at $41^{\circ} \mathrm{C}$.

At two humidities, corresponding to 13.4 and $58.2 \mathrm{~mm} \mathrm{Hg}$, fuel consumption, power, and optimum spark advance readings were taken at 12 points over the range of air-fuel ratios stated above. Results are shown in Figures 3 and 4. 


\section{DISCUSSION OF RESULTS}

The tests shown in Figure 1 indicate a linear relation between loss of power and absolute humidity; the more extensive tests by Gardiner agree with this. Moreover, if the humidity be expressed as percentage of barometric pressure, the loss of power in percentage is roughly equal to the humidity. From this has arisen the "oxygen content" hypothesis, stating that the power is proportional to the oxygen content of unit volume of the atmosphere.

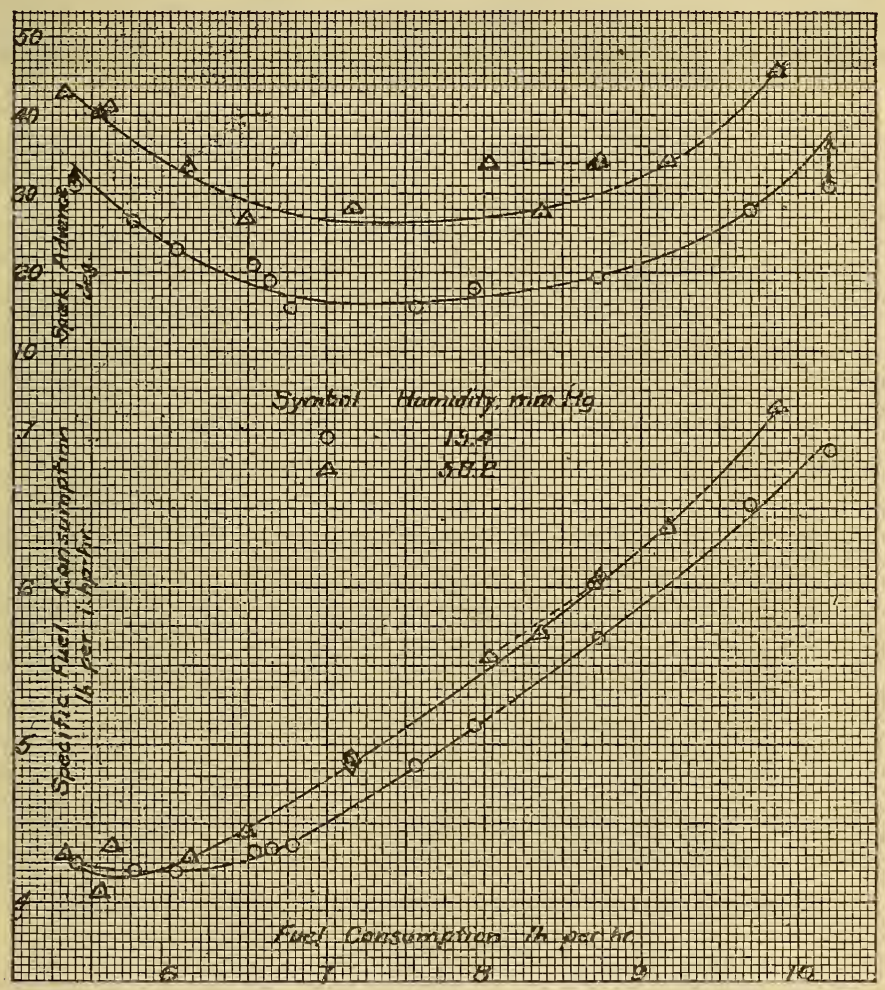

FIgURE 4.-Effect of humidity on specific fuel consumption

To test this hypothesis, values of loss of maximum power from the three series of tests were plotted against the loss predicted on the basis of the oxygen content hypothesis. Figure 5 shows the agreement between the measurements and the hypothesis, the weighted mean observed loss of power being 101 per cent of that predicted. However, other factors than decrease in oxygen content may affect the power.

Figure 6 summarizes the results in regard to variation of optimum spark advance with humidity. A decided increase in spark advance is seen to be required with increasing humidity. This rate of increase seems to be a constant, irrespective of the magnitude of advance. 
The upper curve is the mean of observations by Gardiner on another engine, operating at different speed and compression ratio and with generally different operating conditions. For all these curves, however, the required advance is $2.1^{\circ}$ per $\mathrm{cm} \mathrm{Hg}$ of water-vapor pressure within the limits of experimental error. On the basis of curves presented in N. A. C. A. Technical Report No. 276, and if the progress of combustion is similar at all humidities, this rate of increase of spark advance should entail a loss of power equal to 13 per cent of that due to the decrease of oxygen; that is, if only oxygen content and spark advance affect the power, the loss of power should be 113 per cent of that predicted on the basis of the "oxygen content" hypothesis.

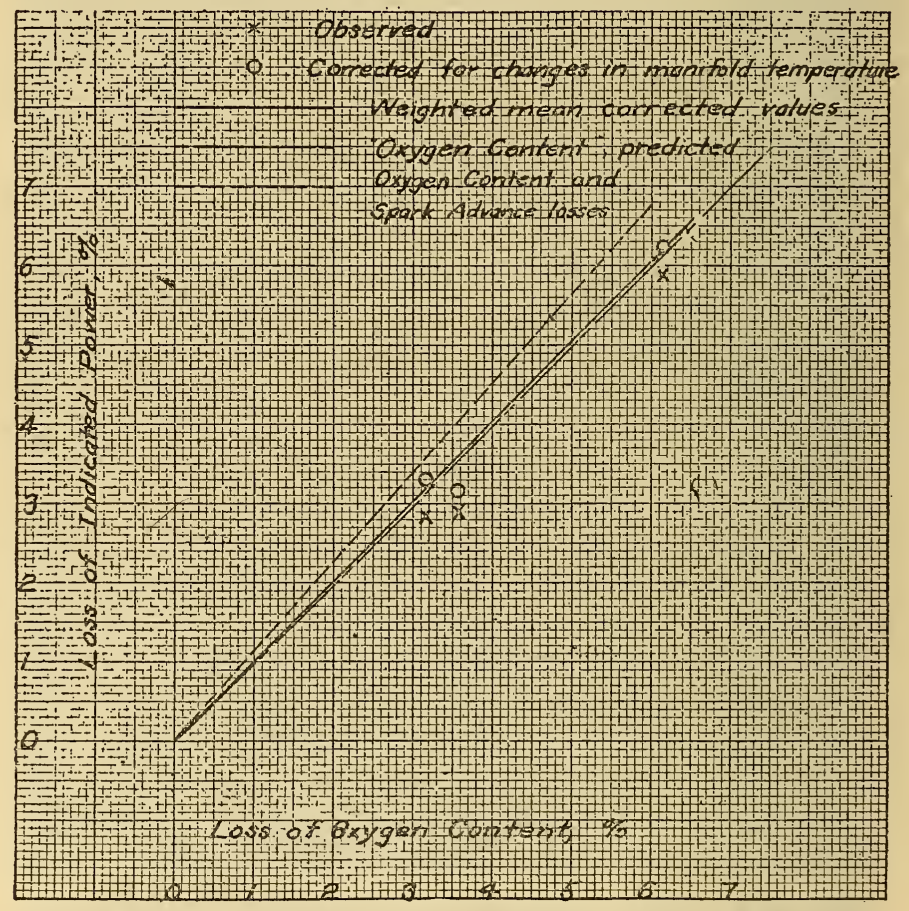

FIgURE 5.-Summary of tests showing effect of humidity on power

On the basis of the Bureau of Standards tests, which show but 101 per cent \pm 2.6 per cent of the loss predicted from the oxygen content hypothesis, there is a 99.8 per cent probability that other factors tend to compensate for the loss occasioned by reduction of oxygen and increase of optimum spark advance. Such other factors may include lower radiation, dissociation, and less change of specific heats, due to lower maximum temperatures.

In Figure 4 it is seen that the specific fuel consumption curves at the two humidities are displaced horizontally but have practically the 
same minimum. Moreover, this horizontal displacement is equal, in per cent, to the percentage difference in oxygen content. This indicates that fuel consumption as well as power should be corrected for change in humidity, since fuel consumption is used in place of airfuel ratio. This has been done for test series No. 3, in Figure 7. The results obtained at the two humidity values are seen to lie on the same curve within experimental error.

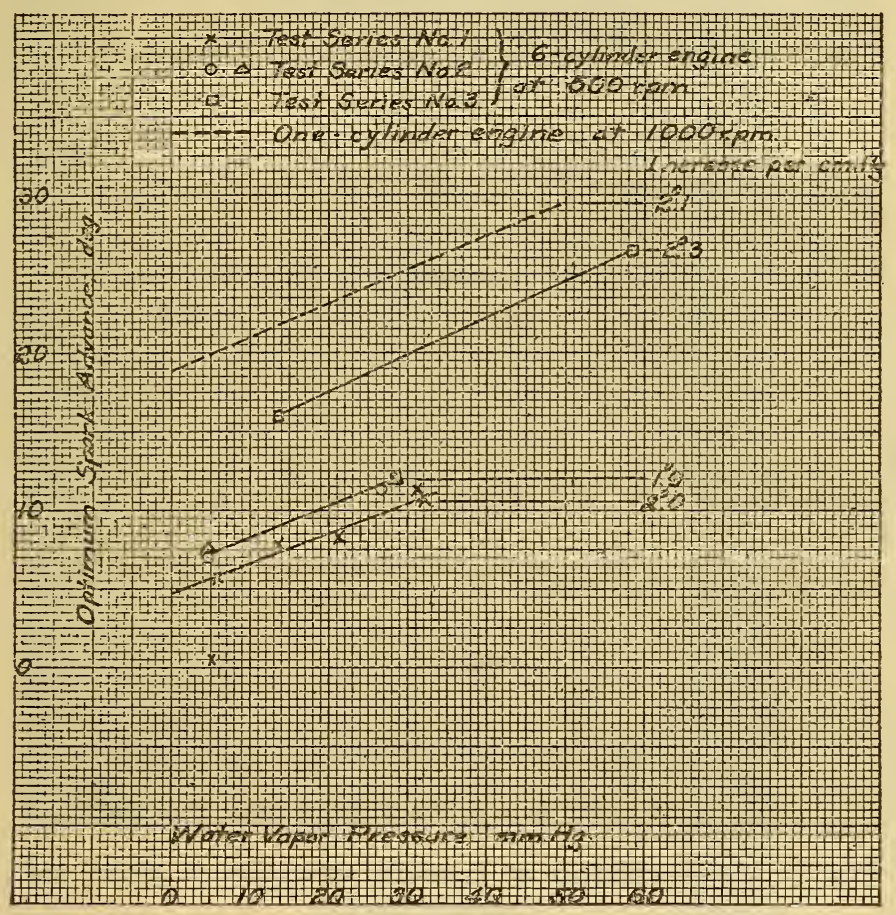

FIGURE 6.-Effect of humidity on optimum spark advance

\section{HUMIDITY CORRECTION CHART}

Figure 8 is a nomogram for obtaining water-vapor pressure (humidity correction to barometer) from wet and dry bulb and barometer readings. Figure 8 is constructed for units of ${ }^{\circ} \mathrm{C}$. and $\mathrm{mm} \mathrm{Hg}$. Figure 9 is a similar nomogram for units of ${ }^{\circ} \mathrm{F}$. and inches $\mathrm{Hg}$.

To use these charts, place a straightedge so that it intersects the $t-t^{\prime}$ scale at the value of the difference between wet and dry bulb readings and intersects the $t^{\prime}$ scale at the value of the wet-bulb temperature. At its point of intersection of the true (corrected) barometer value read the humidity in the units shown on the scale at the extreme right.

For convenience a barometer-temperature correction nomogram is located at the lower right of the chart. To use this, align a straight- 
edge through the center of the small circle at the bottom of the chart and through the barometer temperature on the vertical scale to the right. At its intersection with the observed barometer reading read barometer correction on the same scale used for humidity correction. This correction chart is for barometers with brass scales.

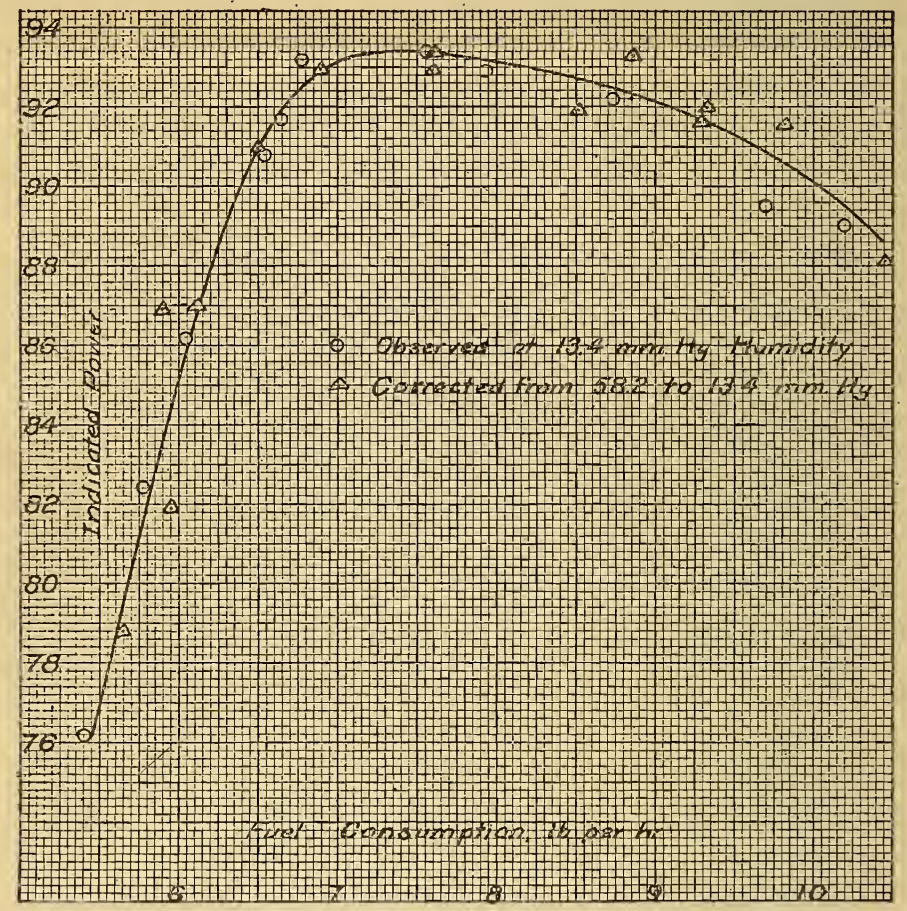

FIgURE 7.-Verification of humidity correction to power and fuel consumption

The humidity charts are based on Smithsonian values ${ }^{3}$ for watervapor pressure and on the formula deduced by Professor Ferrel ${ }^{4}$

$$
e=e^{\prime}-0.000367 B\left(t-t^{\prime}\right)\left(1+\frac{t^{\prime}-32}{1,571}\right)
$$

for English units in which

$e=$ pressure of water vapor in inches $\mathrm{Hg}$ corresponding to dry and wet bulb temperatures $t$ and $t^{\prime}$ in ${ }^{\circ} \mathrm{F}$., respectively.

$B=$ true barometric pressure in $\mathrm{Hg}$.

$e^{\prime}=$ saturation water-vapor pressure at $t^{\prime}$, and on the same formula with appropriate constants for metric units.

3 Smithsonian Meteorological Tables.

4 Annual Report of the Chief Signal Officer, Appendix 24, pp. 233-259; 1886. 

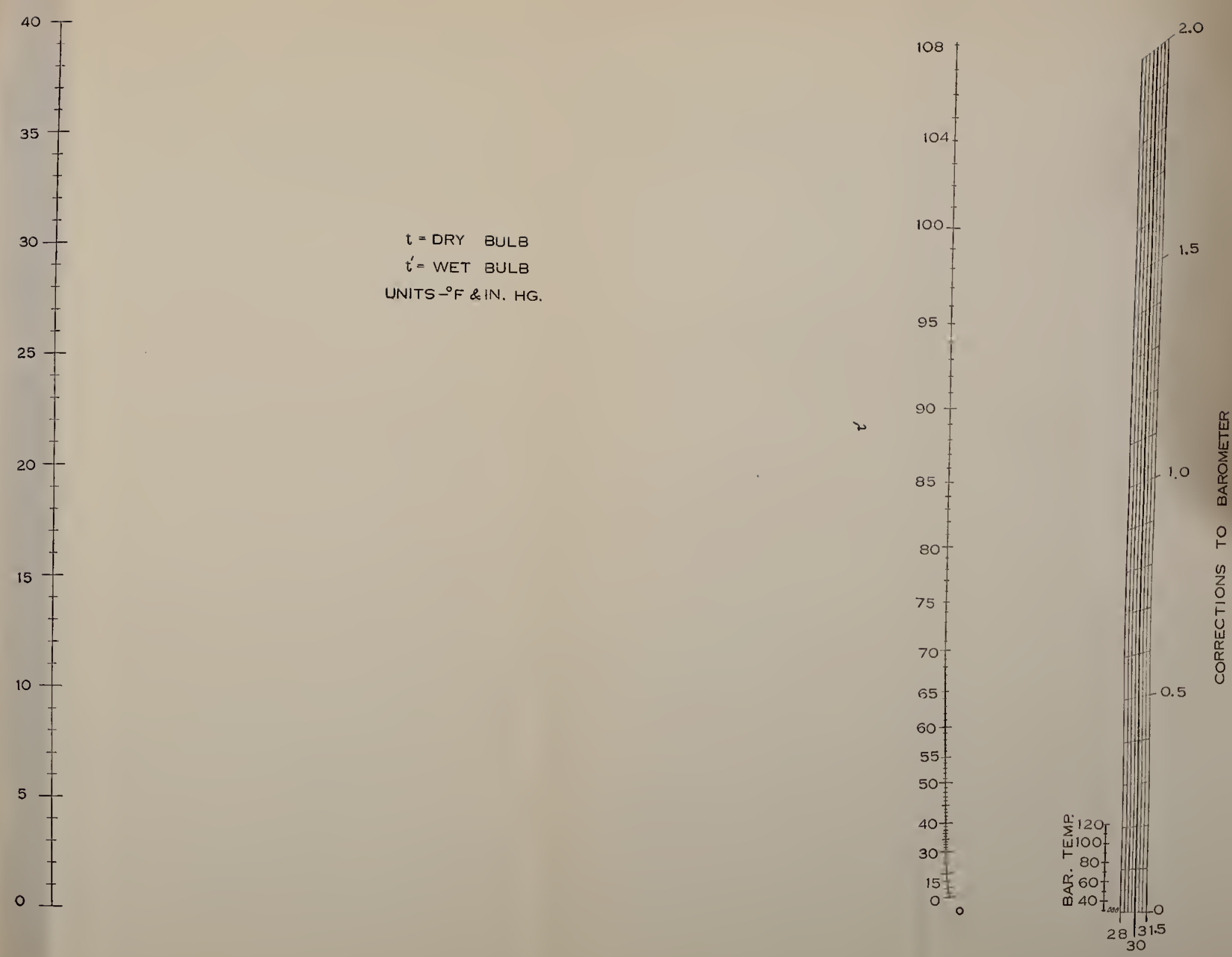
It is to be noted that these charts assemble barometer corrections significant in automotive work on one sheet, are sufficiently precise for their purpose, and are less laborious and less productive of errors of computation than psychrometric tables or contour charts. Other barometer corrections include free-air altitude, latitudè, and capillarity. The first two of these total less than $1 \mathrm{~mm}$, while the latter is of the opposite sign and of much the same magnitude; hence, these three corrections are negligible for automotive work in this country.

In correcting engine-performance data to standard conditions corrections for both humidity and barometer temperature are to be subtracted from the observed barometer reading to give air pressure. Observed power and corresponding fuel flow are then multiplied by the pressure correction factor (standard pressure/air pressure), thus allowing for variations in atmospheric pressure and humidity.

\section{CONCLUSIONS}

1. This work shows definitely that failure to allow for the effect of differences in atmospheric humidity may introduce errors as great as would be occasioned by failure to allow for changes in barometric pressure. Under extreme conditions either correction may amount to nearly 10 per cent of the indicated power.

2. Under all atmospheric conditions normally encountered in automotive testing, humidity may be allowed for by deducting the observed pressure of water vapor from the barometric pressure used in the power computations.

3. Due to cancellation of opposing factors the proposed correction represents the observed effect of humidity well within the usual precision of power measurements.

4. In correcting engine-performance data at different air-fuel ratios the fuel flow values must be multiplied by the same coefficient as the power values.

5. Optimum spark advance increases linearly with increasing humidity.

6. Charts are presented for the convenient determination of humidity values.

\section{APPENDIX-METHOD OF COMPUTATION OF CHARTS}

The Ferrel formula for computation of absolute humidity viz,

$$
e=e^{\prime}-0.000367 B\left(1+\frac{t^{\prime}-32}{1,571}\right)\left(t-t^{\prime}\right)
$$

reduces, for a selected value of $B$, to

$$
e=e^{\prime}-\left(a+b t^{\prime}\right)\left(t-t^{\prime}\right)
$$

where $a$ and $b$ are constants derived from the Ferrel formula, $e^{\prime}$ is the water vapor pressure at $t^{\prime}$, and $e$ the absolute humidity at $t, t^{\prime}$. 
With this as a basis, the chart is constructed as follows: Suitable scales are selected for $\left(t-t^{\prime}\right)$ and for $(e)$, as in Figure 10. Let the length corresponding to one unit of $\left(t-t^{\prime}\right)$ be $m$; the vertical length corresponding to one unit of $(e)$ be $n$; and the horizontal distance between the $\left(t-t^{\prime}\right)$ and $(e)$ scales be $p$. The $t^{\prime}$ scale is then located

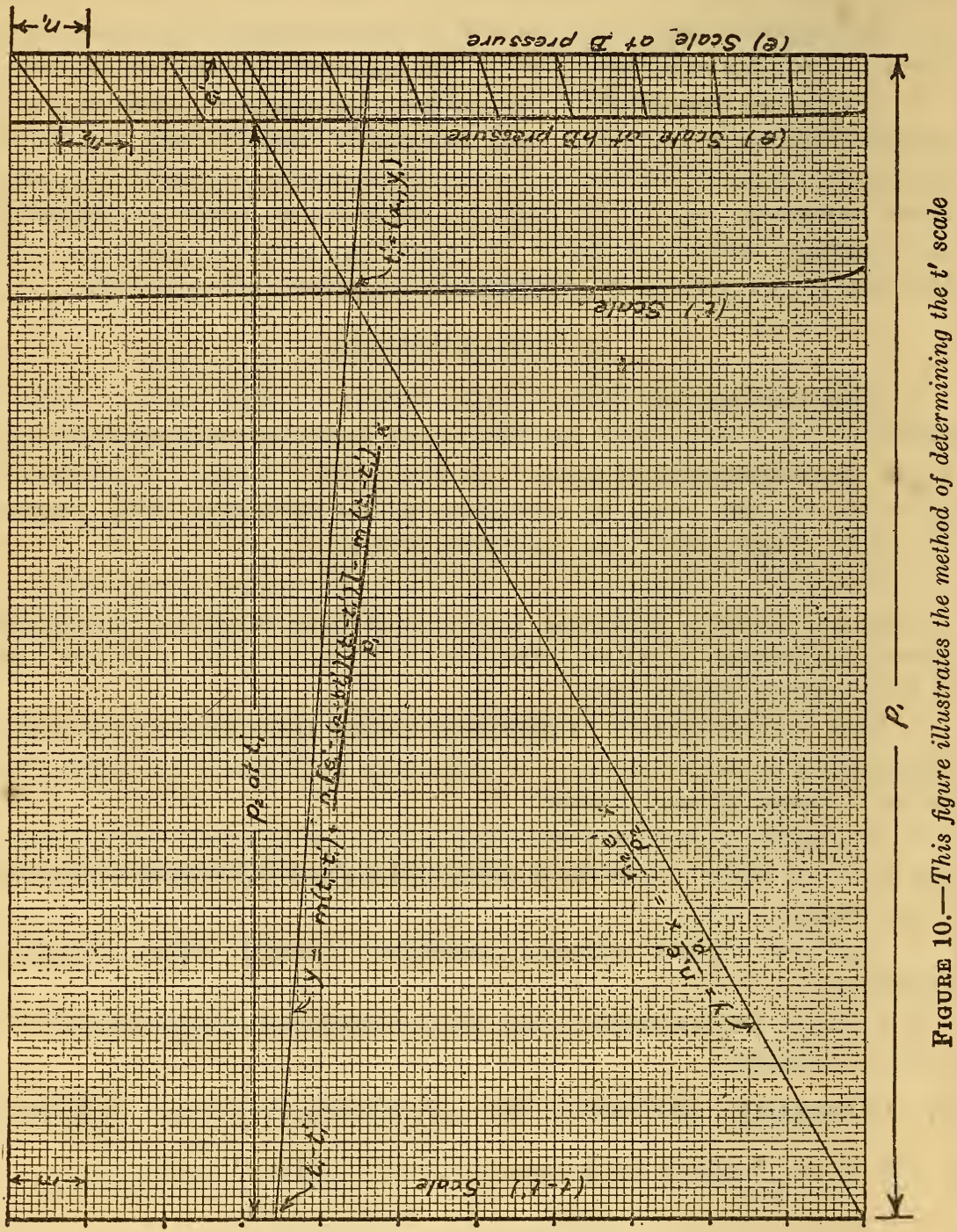

by the following considerations: When $\left(t-t^{\prime}\right)$ is 0 , the vapor pressure is obviously $e^{\prime}$, the saturation pressure at $t^{\prime}$. When $\left(t-t^{\prime}\right)$ has any value, the vapor pressure is

$$
e_{1}=e_{1}{ }^{\prime}-\left(a+b t_{1}{ }^{\prime}\right)\left(t_{1}-t_{1}{ }^{\prime}\right)
$$


If a line be drawn from 0 on the $\left(t-t^{\prime}\right)$ scale to $e^{\prime}$ on the $(e)$ scale, and another line from any other value on the $\left(t-t^{\prime}\right)$ scale to the corresponding value on the $(e)$ scale as given by (2a), the intersection of these lines fixes the corresponding value of $t_{1}{ }^{\prime}$ on the $\left(t^{\prime}\right)$ scale. In terms of the scale divisions, the equations of these lines are

$$
y=\frac{n e_{1}^{\prime}}{p_{1} x}
$$

and

$$
y=m\left(t_{1}-t_{1}{ }^{\prime}\right)+\frac{n\left[e_{1}{ }^{\prime}-\left(a+b t_{1}{ }^{\prime}\right)\left(t_{1}-t_{1}{ }^{\prime}\right)\right]-m\left(t_{1}-t_{1}{ }^{\prime}\right)}{p_{1}} x
$$

The solution for the point of intersection gives

$$
\begin{aligned}
& x=\frac{p m}{m+n a+n b t^{\prime}} \\
& y=\frac{m n e}{m+n a+n b t^{\prime}}
\end{aligned}
$$

where subscripts have been dropped, as the solution is general, giving the locus of the $t^{\prime}$ scale in terms of functions of $t^{\prime}$. It is to be noted that the solution for $x$ and $y$ does not contain $\left(t_{1}-t_{1}{ }^{\prime}\right)$; hence, the requirements of equation (2) are satisfied by a line. This verifies the choice of the nomogram. From specific values of $x$ and $y$ from (5) the $t^{\prime}$ scale is constructed.

In subsequently constructing scales for values at different barometric pressures the following considerations apply. Since $x$ and $y$ are now to be regarded as fixed, it is desired to alter $p$ so that equation (1) shall be satisfied at some other barometric pressure. Calling the new barometric pressure $h B$, and letting

$p_{1}=$ value of $p$ with $B$ barometric pressure,

$p_{2}=$ value of $p$ with $h B$ barometric pressure,

then, from (3),

where

$$
\frac{n_{1}}{p_{1}}=\frac{n_{2}}{p_{2}}
$$

$n_{1}=$ value of $n$ with $B$ barometric pressure,

$n_{2}=$ value of $n$ with $h B$ barometric pressure.

Since $x$ also is to be fixed, from (5)

$$
\frac{p_{1} m}{m+n_{1}\left(a+b t^{\prime}\right)}=\frac{p_{2} m}{m+n_{2} h\left(a+b t^{\prime}\right)}
$$




$$
\begin{aligned}
& \tau=\text { DRY BULB } \\
& t^{\prime}=\text { WET BULB } \\
& \text { UNITS- }{ }^{\circ} \mathrm{C} \& \mathrm{MM} \text {. HG. }
\end{aligned}
$$

ALTITUDE, FT.
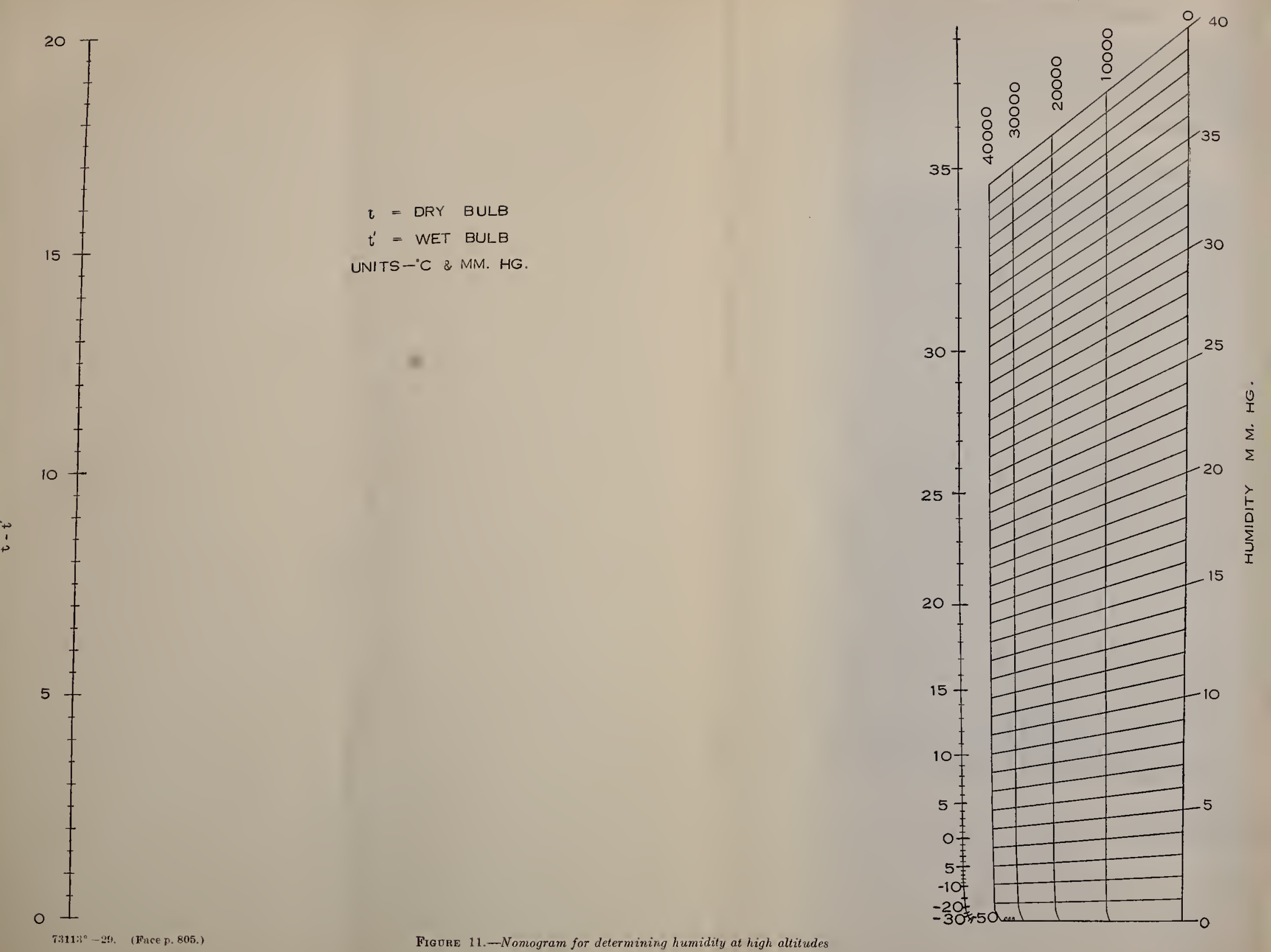

FIGURE 11.-Nonogram for determining humidity at high altitudes 
Hence,

$$
\begin{aligned}
& m p_{1}+n_{2} h a p_{1}+n_{2} h b t^{\prime} p_{1}-m p_{2}-n_{1} a p_{2}-n_{1} b t^{\prime} p_{2}=0 \\
& m\left(p_{1}-p_{2}\right)=n_{1} a p_{2}(1-h)+n_{1} b t^{\prime} p_{2}(1-h) \\
& m\left(p_{1}-p_{2}\right)=n_{1} p_{2}\left(a+b t^{\prime}\right)(1-h) \\
& \frac{p_{1}-p_{2}}{p_{2}}=\frac{n_{1}\left(a+b t^{\prime}\right)(1-h)}{m} \\
& \frac{p_{1}}{p_{2}}=\frac{n_{1}\left(a+b t^{\prime}\right)(1-h)+m}{m} \\
& p_{2}=\frac{m p_{1}}{m+n_{1}(1-h)\left(a+b t^{\prime}\right)}
\end{aligned}
$$

which defines $p_{2}$, and hence $n_{2}$ in terms of known quantities.

Figure 11 is a chart for determining humidity in connection with high altitude tests, constructed on the basis of (8). From this chart it is seen that $p_{2}$ is sensibly constant with $t^{\prime}$. Figures 8 and 9 are based on the Smithsonian Tables, in which $p_{2}$ can be found from the relation

$$
p_{2}=p_{1}-k(1-h)
$$

in which $k$ is a constant for values of $h$ near unity.

Washington, April 20, 1929. 